\title{
Infecção por Enterobius vermicularis em população pré-colombianas no Chile
}

\author{
- Escola Nacional de Saide \\ Pública - Fiocruz - Rio de \\ Janeiro \\ **Instituto de Biologia UFRRJ \\ ** Universidad del Norte, \\ Antofagasta - Chile
}

\author{
Luis Fernando Ferreira * \\ Benjamim Martins R. Filho* \\ Adauto José G. de Araújo* \\ Ulisses $E$. Confalonieri ${ }^{* *}$ \\ Lautaro Nuñez ***
}

O encontro de parasitos em corpos mumificados ou em coprólitos coletados em sítios arqueológicos contribuem para o estudo da origem, evolução e introdução de doenças parasitárias em populações do passado, bem como fornece dados sobre essas populações, comportamento quanto à habitação, deslocamentos migratórios, hábitos alimentares e tamanho de população.

Em coprólitos coletados por um de nós (L.N.), no sítio arqueológico de Caserones, no vale de Tarapaca, norte do Chile, encontraram-se ovos de Enterobius vermicularis. As camadas em que se coletaram os coprólitos foram datadas de $400 \mathrm{AC}$ a $800 \mathrm{AD}$.

O Enterobius vermicularis é um parasito intestinal do homem, cuja sintomatologia principal é o aparecimento de prurido na região peri-anal. A infecção se faz por via direta, através da ingestão dos ovos que são eliminados pelas fêmeas, contaminando a região peri-anal e assim as mãos e os alimentos. Pode-se encontrar também os ovos nas fezes. Observa-se que, em comunidades fechadas, principalmente crianças em orfanatos ou creches, a prevalência da infecção é muito grande, atingindo a quase totalidade das pessoas.

Em populações pré-históricas, que viviam em grutas ou acampamentos, o encontro deste parasito pode indicar uma infecção em todo o grupo devido a este tipo de transmissão direta.

O Enterobius vermicularis já foi assinalado em alguns sítios. arqueológicos na América ${ }^{3,4,5}$ e, embora não tenha sido encontrado em coprólitos na Europa, existem evidências indiretas, através de documentos antigos, de sua presença em populações da China, Grécia, India e Arábia, antes de Cristo.

Pelo mecanismo de transmissão direta, de homem a homem, sem passagem pelo meio ambiente, não são possíveis informações sobre rotas migratórias, como no caso de Ancilostomídeos e Trichuris ${ }^{1,2}$.

\section{REFERÊNCIAS BIBLIOGRĀFICAS}

1. FERREIRA, L.F. et alii. The finding of helminth eggs in 
archaeological material from Unai, Minas Gerais, Brasil. Trans. R. Soc. Trop. Med. Hyg., 74: 798-800, 1980.

2. FERREIRA, L.F. et alii. The finding of helminth eggs in a Brazilian mummy. Trans. R. Soc. Trop. Med. Hyg., 77 (1): 65-7, 1983.

3. FRY, G.F. \& MOORE, J.G. Enterobius vermicularis 10.000 years-old human infection. Science, 166:1620, 1969.

4. PATRUCCO R. et alii. Parasitological studies of cropolites of Pre-Hispanic Peruvian population. Curr. Anthropol., 24 (3) Jun., 1983.

5. ZIMMERMAN, M.R. \& MORILLA, R.E. Enterobiasis in pre Columbian America. Paleopathol. Newsl., (42) Jun., 1983.

\section{A competição biológica como método alternativo para o controle dos transmissores da esquistossomose.}

Frederico Simões Barbosa ${ }^{*}$

Trabalhos que vêm sendo desenvolvidos nos estados de Pernambuco e da Paraíba, há alguns anos, sobre o controle biológico dos moluscos transmissores da esquistossomose, revelaram que Biomphalaria straminea tem comprovada capacidade competitiva sobre $B$. glabrata.

Trabalhando com uma cepa de $B$. straminea resistente a infecção por Schistosoma mansoni os pesquisadores do Centro de Pesquisas Aggeu Magalhães, em Recife, demonstraram que, em ambiente seminatural criado no laboratório, $B$. straminea tem a capacidade de deslocar totalmente a população-alvo de $B$. glabrata dentro do período de cerca de dois anos. O mesmo fenômeno ocorre com outra cepa de $B$. straminea semi-resistente a infecção por $S$. mansoni, nas mesmas condiçðes acima.

Outros aspectos da competição foram estudados em laboratório, ficando demonstrada a superioridade do competidor contra a população-alvo. Assim, B. straminea tem maior capacidade de dispersão, vagilidade e resistência à dessecação que $B$. glabrata $^{1}$.

$O$ experimento de campo vem revelando que o fenômeno ocorre com as mesmas características de deslocamento competitivo entre duas populaçðes. No momento, dois anos
* Escola Nacional de Saúde Pública - FIOCRUZ, Rio de Janeiro e Centro de Pesquisas Aggeu Magalhaes - FIOCRUZ, Recife-PE. 